awoke in the morning with no knowledge of the night's events, though quite clear as to the experiences of the evening before. Gradually these reinstatements became more frequent and of longer duration, and resulted in an intense and painful struggle which Mr. Hanna afterward recounted as one of the most trying moments of his life, when he really seemed forced to choose between the two personalities, each of which seemed to claim him as its own, and yet with no exclusive right. The saving alternative, which was the issue of the struggle, was to embrace them both, to merge the two, though with imperfect conviction, until they gave way to the normal state of affairs.

The case is important and interesting, not only by reason of its general progress, but on account of the many detailed observations that enrich the account, and suggest at each step well-formulated and specific problems in regard to psychological principles and analyses. These are further discussed in a series of introductory chapters, and in another series of concluding chapters, in which Dr. Sidis presents his general statements in regard to the nature of personality. The trend of these is not easily reproduced, and indeed leaves upon the reader something of a vagueness of impression that is inevitable in our present imperfect understanding of these cases. What is more important is that the interpretation, so far as it goes, is intimately allied with the sanest and safest interpretations of modern psychology, and emphasizes the fundamental importance of the normal subconscious life as the proper starting-point for the interpretation of the abnormal. For all of these merits the volume deserves, as it doubtless will find, a useful place in the psychologist's equipment for the comprehension of the varieties and the variations of personality.

\title{
NEGATIVE SUGGESTIBILITY.
}

$\mathrm{J} \cdot \mathrm{J} \cdot$

Negative Suggestibility, a physiological prototype of negativism, of contrary auto-suggestion and certain obsessions. Professor Bleuler. Psychiat. Wochenschrift, Nos. 27 and 2S, 1904 .

The finest movements are obtained by combination of antagonists and agonists, representing the excess of the power of the agonists. All the peripheral mechanisms such as the heart, intestines, vessels and sphincters have their stimulant and inhibitory nerves. In psychic activity, too, any topic of thought inhibits all the other noncorrelated concepts. If, after all, thought does not always move in one direction, it would seem that association is not merely a selection of favorable and positive tendencies, but that there is at the very bottom of the 
mechanisms of association a provision for the response of directly opposite tendencies. This phenomenon might be classed as association by contrast, but it is so generally present that there is much to be said in favor of the view that there is a special mechanism, a general tendency to associate with every concept also its opposite.

Bleuler gives a number of instances of this principle in the ordinary play of motives in deliberation. In children he notes the balancing of reluctance and eagerness, even where timidity is excluded; he refers to the mixtures of coyness and sexual desire, the balance of fear and eagerness in risks; the tendency to continually touch a painful tooth.

In harmony with their purpose these coupled contrasts appear to arise especially in connection with action. "Those persons who entirely exhaust the pros and cons beforehand and have completely settled their deliberation before they begin to act are rare types." With most people a decision arouses new opposite concepts; but in only a small number a decision suppresses them altogether. In such cases the association of contrasts becomes decidedly undesirable, and it is especially striking that it manifests itself much less in calm deliberation than just before action, where such an elementary mechanism is a truly fundamental protector. In this respect there are profound differences of character.

Bleuler refers to analogous contrasts in feelings, such as laughing in an accident, the perverse actions of unfavorable autosuggestions where a person anticipates the possibility of a headache, or of menstruation at an undesirable date; the tendency to acquire mannerisms which one criticises and ridicules in others; the inability to sleep owing to the excessive eagerness to sleep; the peculiarity of a blocking of the very thoughts one needs (in examinations, etc.); a fear of failure does not explain sufficiently the direction of the inhibition. Everything points to a special mechanism which tends to rouse contrasting or antagonistic concepts. It is especially marked in relatively suggestible individuals as a protection against being taken by surprise; but in the abnormal, too, negativism and suggestibility, automatism and echopraxia, frequently go hand in hand (in dementia præcox), or excessive confiding and yielding beside distrust and obstinancy (in senile dements), or suggestibility beside uncontrollable contrary autosuggestion (in hysteria), etc. Wherever an emotion, or the narrowing of the field of consciousness, or a blocking process, interferes with the course of thought, the elementary process of associative contrasts becomes prominent. 
Suggestibility is a certain side of affectivity; as such it is connected more closely with volition and activity than with ideation; the laboratory test leads to fewer contrast associations than actual life with its volition and activity. Timidity and misoneism are affects of negative suggestion. Emotionally important ideas are especially apt to give rise to negative suggestions when the impulsiveness of activity makes one more in need of this control. As suggestion generally, and affectivity, negative suggestion has an enormous influence also on the physical functions.

Bleuler promises perspectives for the explanation of many symptoms of dementia præcox as qualitatively and quantitatively disfigured mechanisms of normal mental life (through predominance of this fundamental appeal to contrast). He also points to many obsessions, to the contrary autosuggestions of hysteria, and finally refers to some explanations of this phenomenon by other writers.

A. M.

\section{METHODS OF BRAIN RESEARCH.}

Einige Bemerkungen über Untersuchungsmethoden der Grosshirnrinde, insbesondere des Monschen. PAul Flechsig. Sitzungsberichte der Akad. Wiss. Leipzig, Math.-phys. Klasse, Sitzung vom II. Jannar, 1904. Pp. 50-104 and pp. $177-248$ (with 4 plates).

Flechsig herewith presents to the central committee of brain investigation a critical comparison of the various methods of neurolog. ical research, with special reference to his myelogenetic method. For some reason Flechsig has met with emphatic opposition at the hands of most neurologists. By making certain peremptory claims, and by an unfortunate personal vein, he brought upon himself a flood of bitter attacks, which does not reflect very pleasantly on the brotherhood of neurologists. His latest paper gives a rather fair comparative estimate of the fundamental methods of research and an outlook towards better dovetailing of the accessible methods.

In view of the fact that there is already a full review of the essentially anatomical part of the paper of Flechsig, with a copy of several illustrations, from the pen of Florence R. Sabin, in the Jolins Hopkins Hospital Bulletin, Vol. 16, Feb., 1905, pp. 45-49, we can limit ourselves to a few remarks concerning the present status of neurological and neuro-pathological problems.

Flechsig acknowledges the need of a comparative study of all the types of nerve cells and their combinations (such as has its principal representatives in Cajal, Campbell, etc.). He recognizes that most of 